\title{
From takeover to debacle: An analysis of the Nymphgate network using Twitter data
}

\author{
Maria Paula Arias
}

\begin{abstract}
On 26 January 2018 the painting Hylas and the Nymphs was temporarily removed from the Manchester Art Gallery's walls and taken underground to its store. The removal was part of a 'takeover' event that questioned the relationships between historic works of art and contemporary social-cultural contexts. The following days saw a barrage of online comments accusing the Gallery of censorship, of 'feminism gone mad', and of inadequacy. In this article I use Twitter data and Actor Network Theory to explore how a community and a narrative took shape around the takeover. The analysis shows how this Nymphgate network was influenced by a series of human and non-human actors, as well as by Twitter's technological affordances. This study is part of a larger project, as such it leads to question the potential effects of this mediatized debacle to the Gallery's organizational strategy - including the roles of, and relationships between, decision-makers, social media, and visitors within it.
\end{abstract}

Key words: Twitter, Actor Network Theory, social media analysis, content analysis

\section{Introduction}

On 26 January 2018 under the watchful eyes of Sonia Boyce (contemporary artist) and Clare Gannaway (curator of contemporary art), the painting Hylas and the Nymphs was carefully removed from the Manchester Art Gallery's walls and taken underground to its store. The removal was part of a 'takeover' event and one of six performative acts of that night, which were filmed by the artist's crew and witnessed by a select group of staff members and visitors. The painting was replaced by a poster (Figure 1) that briefly explained its absence in two ways: to 'prompt conversation' about the relationships between historic works of art and contemporary social and cultural contexts; and as an action taken by 'people associated with the Gallery' in relation to Boyce's then upcoming exhibition.

Those invited to be present during this event were encouraged to take part using post-its as well as participating online both through social media platforms using the hashtag \#MAGSoniaBoyce and in the comments section of the Gallery's ${ }^{1}$ blog. $^{2}$ All of these actions, from inviting an artist for a takeover event to engaging visitors through online and offline tools, can be considered as part of a typical (almost mundane) repertoire of activities that museums and galleries rely on to use their collections to connect with audiences. For the Manchester Art Gallery, it certainly seemed like any regular day until, that is, an unprecedented set of actors changed the tone of the conversation and the rate at which the dialogue was taking place.

In this article I will analyze the responses and reactions to the removal of Hylas and the Nymphs posted by Twitter users (informally known as 'Nymphgate'), using a mixedmethodology to look at how this event spread on the platform and to understand the main themes in this conversation. I approach the takeover through the lens of Actor Network Theory - in doing so, I suggest that the Nymphgate conversation took shape as a network of inter-related actors (online and offline), including: Twitter users, members of staff at the Gallery, media articles and a (temporarily) absent painting. By following a framework that is based on the relationality and performativity of actors (Law 1999), I will explore how this Nymphgate network was shaped by the technological affordances of the platform, through the influence of particular actors, and by the conversations between users. 


\section{We have left a temporary space here in place of}

Hylas and the Nymphs by JW Waterhouse

to prompt conversation about how we display and interpret artworks in Manchester's public collection. How can we talk about the collection in ways which are relevant in the 21 st century?

\section{Here are some of the ideas we have been talking about so far. What do you think?}

- This gallery presents the female body as either a 'passive decorative form' or a'femme fatale'. Let's challenge this Victorian fantasy!

- The gallery exists in a world full of intertwined issues of gender, race, sexuality and class, which affect us all. How could artworks speak in more contemporary, relevant ways?

- What other stories could these artworks and their characters tell? What other themes would be interesting to explore in the gollery?

The act of taking down this painting was port of a group gallery tokeover that took place during the evening of 26 January 2018 . People from the gallery team and people associated with the gallery took part. The takeover was filmed and is part of an exhibition by Sonia Boyce, 23 March2 september 2018.

\#MAGSoniaBoyce

To be continued...

\section{Figure 1. Takeover Poster (credit: Manchester Art Gallery)}

\section{Framing Social Media in Museums}

Social media are Internet-based tools that mediate communication between people, as well as between people and institutions. With these tools, users can 'opportunistically interact and selectively self-present, either in real-time or asynchronously' (Carr and Hayes 2015: 50) as well as collaborate 'around affinities of interest' (Drotner and Schrøder 2013: 3), and form relationships around 'everyday togetherness' (Lomborg 2011: 65, cited in Drotner and Schrøder, 2013: 3). Social media are particularly interesting for museums (in practice and research) because of their disruptive effects on the 'text and user dimensions' (Drotner and Schrøder, 2013: 3). In other words, social media offer a so-called 'democratic' virtual space where all kinds of users may create and share information, determine how others interact with content and therefore the value attributed to these relations and their outputs.

Jenny Kidd suggests that the ways museums have been adopting social media can be understood within three 'organizing frames': marketing, inclusivity, and collaborative (Kidd 2011). These frames encompass the various roles social media enact within institutions that range from broadcasting information and fostering communities, to enabling the co-production of 'the narratives of the museum' (Kidd 2011: 70). Implied in these framings is a 'technological frame' that enables a range of relationships between institutions and their audiences - which may also include negotiating authority, as is the case of the 'collaborative frame'. In this sense, using social media may lead to reframing the 'power relationships' (Meecham 2013) between institutions and their audiences through organizational change (Kelly 2013).

When the Gallery asked their audiences to join in a conversation by questioning their existing interpretative frame, they effectively gave way to renegotiating their relationships not only with their collection but also with their audiences. Kidd suggests that the success of using social media in a 'collaborative frame' requires an alignment between the context of the activity, 
participants' expectations, and how this participation is valued (Kidd 2011: 72). To maintain this alignment we must then examine the relationships between those involved and how these develop over time. To do so, we can turn to Actor Network Theory to better understand how actors organize themselves and create content in and through their relationships.

\section{Sociology of Associations}

Actor-Network Theory (ANT) offers a flexible framework that 'assumes the radical indeterminacy of the actor' (Callon 1999: 181, original emphasis) - meaning that actors determine themselves through their associations with others, which leads the researcher to consider actors of all kinds (human, non-human, and other networks). Latour, referring to a sociology of associations, suggests that as actors structure themselves and determine their roles in relation to others, there is a 'constant tracing of boundaries by people over some other people' (Latour 2005: 21) - in doing so, groups are constantly forming and re-forming themselves. In this sense, actors identify themselves in relation to one another as well as in their continuous performances of these relations.

Networks, then, are sustained through these performances and are uncertain as to the extent to which actors maintain immutable relationships with one another (Law 1999). Similarly, when actors alter their performances, they are not only changing how they relate to others within the network - they are also changing how they identify themselves within it. From this perspective, actors' roles are legitimated through their continued performances and in doing so they maintain the network through time. Law further argues that as actors identify themselves, they are effectively generating knowledge through ordering - including 'patterns of deletion' and 'modes of silence' (Law 1994: 111). Ordering, then, is a characteristic and a result of the asymmetric relationships between actors, which can influence how certain actors within a network are represented, how much agency they have, and (arguably) the influence of their role within the network.

As an analytic tool, ANT can help us then to understand how particular networks are organized by approaching its constituting actors through a lens of relationality and performativity. To do so, Michel Callon proposes three methodological principles to guide researchers: agnosticism, generalized symmetry, and free association (Callon 1986: 200-1). Callon asks the researcher to be impartial to actors' narratives as they describe themselves and others, even in cases where identity or roles are still being negotiated. He also asks the researcher to use the same language to describe the viewpoints of both human and nonhuman actors, thus giving both types the same potential in order and affiliation. Finally, Callon asks the researcher to 'abandon all a priori distinctions between natural and social events' (Callon 1986: 201) in order to follow actors' narratives without censorship and to be able to consider the actors within the same descriptive plane.

Overall, ANT asks the researcher to let actors 'speak for themselves' and to not make any assumptions towards the structure of the network, nor the actors' modes of ordering or silencing. To this end, I have made specific choices about the methods I used to collect, interpret, and present the data for this case study. For example, throughout this article I use the terms 'community' to describe actors and 'conversation' to describe their relationships. This choice reflects Kozinets' description of 'consociality' where a group of people is temporally aggregated in a 'contextual fellowship' (Kozinets 2015: 11-2). In this case, the Nymphgate community (or network) is composed of diverse actors who: are a subset of the overall Twitter user base, share a 'contextual fellowship' in their responses to the Gallery's actions, and influence the flow of information through their online 'conversations'.

In this article, social media is used as a short-hand for the platforms that enable users to engage with one another in a 'network', and so it acknowledges the constitutive elements José van Dijck assigns to these platforms: technology, users and their usage, content, ownership, governance, and business models (van Dijck 2013: 29-41). Here, I am focusing on the first three elements: technology, users, and content. To this end I have collected Twitter data using TAGS (Twitter Archive Google Sheets). ${ }^{3}$ TAGS uses Twitter's Search API to archive and display search results on a Google Spreadsheet and, as such, it is tied to the Twitter's search limitations - meaning that TAGS can only collect from Twitter's search index, which 
includes '6-9 days of Tweets' and archive 'up to $1 \%$ of the total volume of tweets in the world at any one point in time'. ${ }^{5}$

Tweets were archived with TAGS using 13 keywords (Figure 2) relating to the Gallery and individuals involved in the event. These keywords were chosen to reflect the 'official' space created by the Gallery with their event hashtag (\#MAGSoniaBoyce), as well as to capture as much of the 'unofficial' conversation that took place outside it. The resulting dataset includes 21,039 unique tweets posted by 15,471 unique users from 24 January to 10 February 2018. The data collected includes metadata (including information about the user, details about the post such as date of creation, and platform engagement metrics such as likes, retweets, and '@ mentions') and posts' content (including hashtags and links to associated visual media).

\begin{tabular}{|l|l|}
\hline Search Word & Category \\
\hline ClareGannaway & Account \\
\hline MAGcurators & Account \\
\hline magwagdirector & Account \\
\hline mcrartgallery & Account \\
\hline \#hylasgate & Hashtag \\
\hline \#MAGSoniaBoyce & Hashtag \\
\hline \#nymphgate & Hashtag \\
\hline \#objectsofobsession & Hashtag \\
\hline Clare Gannaway & Phrase \\
\hline Hylas and the Nymphs & Phrase \\
\hline Manchester Art Gallery & Phrase \\
\hline nymphgate & Phrase \\
\hline Sonia Boyce & Phrase \\
\hline
\end{tabular}

This data was analyzed in two phases in an attempt to understand how the conversation evolved in and through the Twitter platform and its users. First, I employed quantitative methods to study the metadata using the platforms' predetermined metadata categories thereby creating a timeline of the Nymphgate network, assessing the most popular tweets and users, and comparing users' activity and visibility. Then, I analyzed users' comments through qualitative content analysis - thereby gaining an understanding of the different themes prevalent in the community. In this analysis it was apparent that the way the online conversation took shape was inseparable from the perception of how (in)active

(or silent) particular actors
analyses, I would like to

Figure 2. TAGS Search Words were on and off Twitter. Before moving on to the results of these analyses, I would like to
make a note of the ethical considerations I took for the use of social media data in this project.

\subsection{Ethical Considerations}

For this study I took into consideration Townsend and Wallace's framework for researchers ${ }^{6}$ and the 'ethics of amplification' (Phillips and Milner 2017) as a guideline. To this end, I familiarized myself with Twitter's rules ${ }^{7}$ and user guidelines ${ }^{8}$ as well as TAGS' archiving functions. I used my personal Twitter account to conduct this research and aimed to collect publicly available data only. In keeping with ANT, my intent was to portray the Nymphgate community and conversations as accurately as possible - in the analysis process and in all published materials. As such I employed the same language these actors have chosen to describe themselves and others, which includes using illustrative anonymized tweets without paraphrasing their content.

As I will describer later, a small portion of the dataset contained verbally abusive content - therefore having the potential for further harm in their collection and interpretation. Phillips and Milner describe the 'ethics of amplification' as a responsibility to either amplify or 
limit the potential for harm that is intrinsically available through social media's technological affordances (Phillips and Milner 2017). As such, I have chosen not to illustrate harmful posts in an effort to limit the amplification of these messages. This decision is, of course, entirely subjective and contextually reliant to this study - an alternate decision would be appropriate if a project was concerned with specific harmful behaviours online, for example. With these ethical considerations in mind, I will move now to present the analysis of the Nymphgate conversation.

\section{Twitter Metrics}

Twitter's temporal metrics can be used to describe live events as they unfold; they tell us what went on during an event and how users participated. In this case we can track how the online reactions to the removal of Hylas and the Nymphs developed and how users engaged with one another and with external sources (such as newspapers). The following graph (Figure 3) shows the timeline of the conversation (mapped by the hour) with annotations that correspond to the removal and reinstatement of the painting, and the first media reports of the takeover.

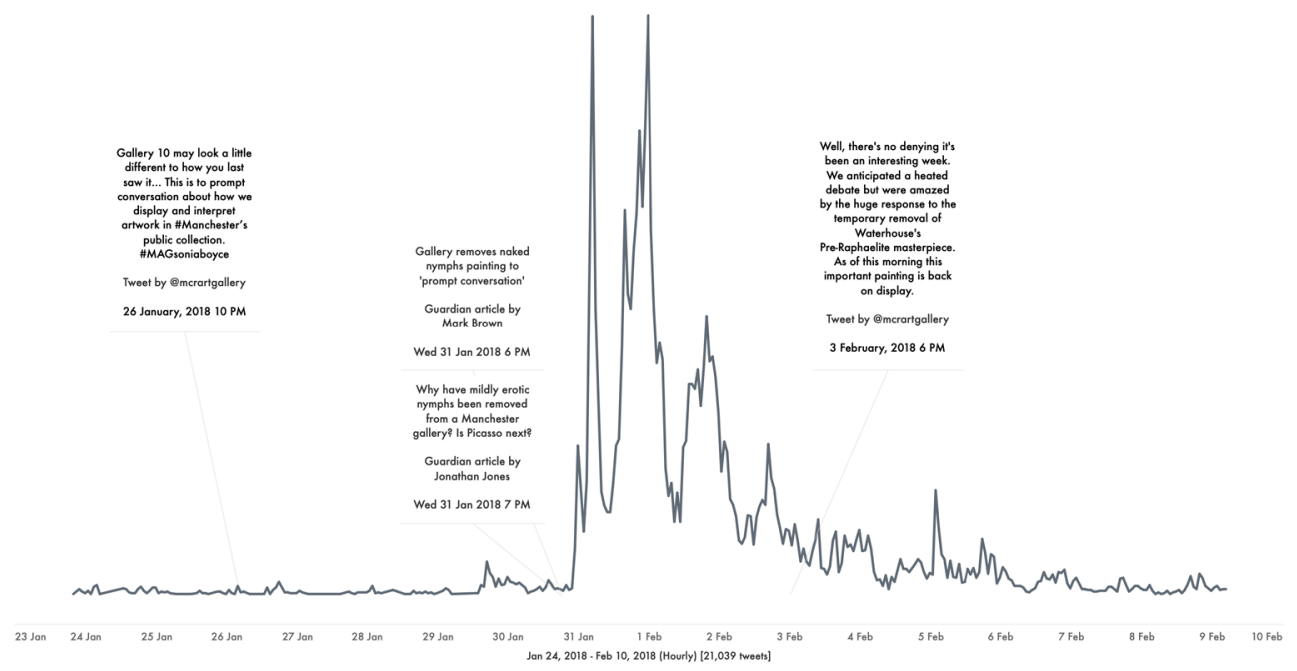

Figure 3. Timeline with Annotations

Two Guardian articles were published on 31 January: one by Mark Brown and another by Jonathan Jones. Both articles were published within hours of each other and each had a particular influence to the Nymphgate community and the Gallery. Jones' article impacted how the Nymphgate conversation was perceived by staff members, which bears a more detailed analysis in a future publication. For now, I will explore the impact of Brown's article first using a quantitative analysis of Twitter metrics and second using a qualitative analysis of tweets' content.

Brown's article ${ }^{9}$ describes the painting and its removal, and includes a handful of images showing post-its left by visitors and the event's hashtag promoting a continued online discussion. Pivotally, the article also includes two brief interviews: one with curator Clare Gannaway and another with one of the visitors who was present during the takeover. Gannaway's comments provided further context to the removal, stating that the gallery in which the painting resides (Gallery 10 or 'In Pursuit of Beauty') $)^{10}$ was a forgotten space and a source of 'embarrassment'. Gannaway further commented that the decisions leading up to the takeover were influenced by the Me Too movement and the Time's Up organization, which at the time had also impacted decisions of the Professional Darts Corporation and Formula One to remove 'walk-on girls' and 'grid girls'. ${ }^{11}$ 
One of the criticisms noted in the article was the accusation of censorship, or as the visitor interviewed said: 'the replacement and removal of art and being told "that's wrong and this is right"'.12 This criticism would resonate online particularly as these initial reports included Gannaway's remark about the removal: 'We think it [the painting] probably will return, yes, but hopefully contextualized quite differently. It is not just about that one painting, it is the whole context of the gallery [In Pursuit of Beauty]. ${ }^{13}$ Brown's article had a series of trigger points that were subsequently used in the tweets following its publishing, ultimately leading to the main themes of the conversation (as discussed below).

\subsection{Expanding Reach}

Any public tweet seen on the platform can be retweeted, which means its content can become visible to extended audiences beyond the original user's. Retweets, therefore, are one of the most important mechanisms within Twitter commonly used as a measurement of successful engagement. ${ }^{14}$ Retweets show what content carries weight in the community and they reveal how information moves in the conversation. In this case, retweets show that Brown's article is one of the most shared pieces of media in the Nymphgate conversation. From the most prominent tweets in this dataset, the top 20 are retweets (Figure 4) - where the majority contain Brown's article as the basis of the user's comment and as a linked visual prompt for the article itself.

Top 20 Tweets by Reference

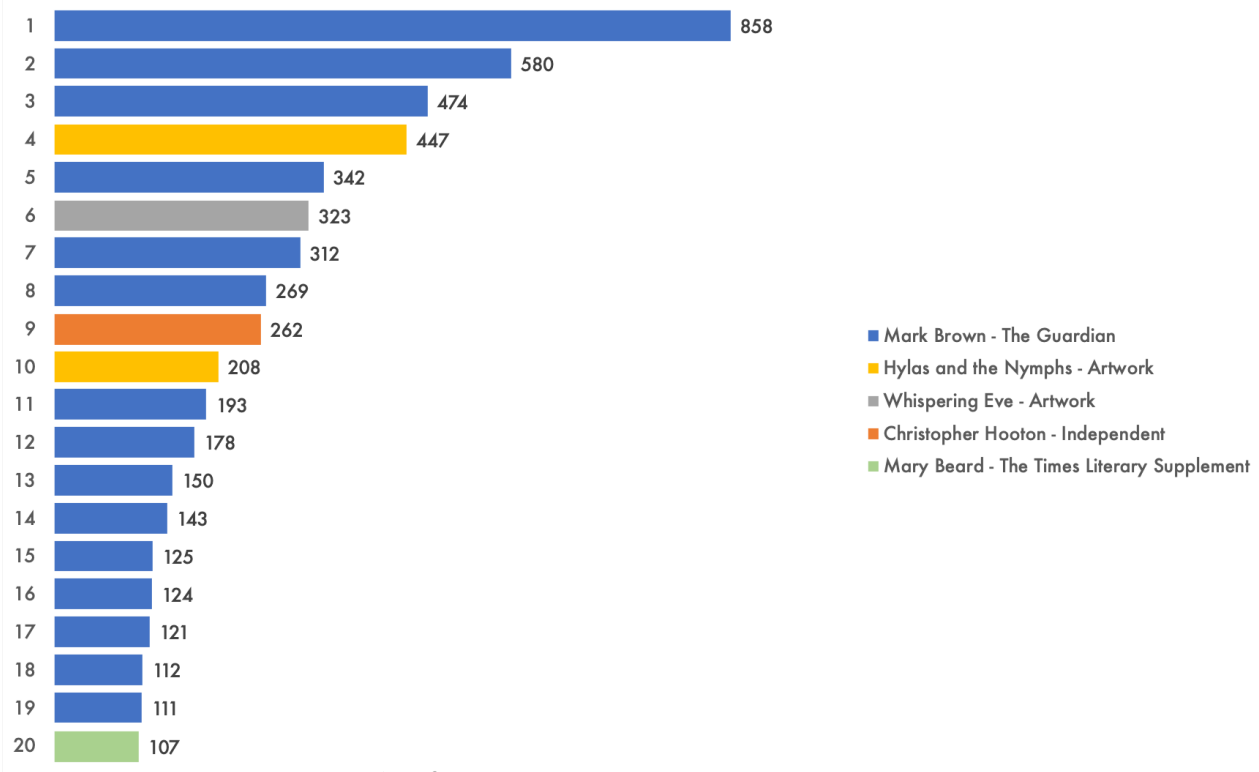

No. of Retweets

Figure 4. Top 20 Tweets by Reference

Although we cannot assume that retweeting is the same as endorsing the original message, retweets are a good indication of interest and attention to particular information. Twitter capitalizes on these behaviours as retweets make posts more visible and therefore also more likely to be retweeted even further, thus creating an environment where a handful of messages get the vast majority of attention. In this case Brown's article was considered valuable currency, so much so that the top retweets that included the article amount to 18.87 per cent of the total dataset. This percentage indicates that the distribution of tweets associated with the Nymphgate conversation closely follows the 'Pareto Principle'15 (Poell and Borra, 2012). This 
principle states that 80 per cent of the effects come from 20 per cent of the causes, which in this case means that the majority of the Nymphgate conversation was influenced by a small selection of tweets containing Brown's article as its base. Here we start seeing evidence of how the Gallery is silent on Twitter and in their perceived absence, the narrative takes shape through other users' actions.

\subsection{Activity and Visibility}

Users' activity can be divided into: original tweets, @mention tweets, and retweets. In doing so, we can see whether users are broadcasting their observations or opinions, whether they're in a conversation with another user (or trying to engage in one), or whether they're sharing someone else's post. Visibility can be measured in @mention tweets and retweets within the overall dataset; this measure can give us insights as to whether users gain visibility within the issues of a particular issue - either as a by-product of the popularity of their content (through retweets) or as the subject of others' content (through @mention). Despite contributing very little to the Nymphgate conversation, the most visible user in the dataset is @mcrartgallery, the Gallery's main account. As Figure 5 shows, the Gallery was not an active member of the Nymphgate conversation (contributing only 26 tweets overall, or 0.124 per cent of the dataset). Rather, the Gallery was a relatively passive actor made visible by the actions of other members of the community.

This pattern suggests that the Gallery was not in conversation with the Nymphgate community, rather the Gallery was the subject of other users' conversations. It is difficult to reconcile the activity (or lack thereof) from the Gallery with the aims of the takeover event - that is, 'to prompt conversation'.16. This pattern resulted in a perception from some of the users that the Gallery asked for a conversation without the intention of actively participating in it, as I will explore later on. Here we start seeing a trend emerge based on the interactions afforded by Twitter's technology and users' performed behaviours, one where the potential influence of certain actors is based on whether or not their presence can be measured by the platform's metrics.
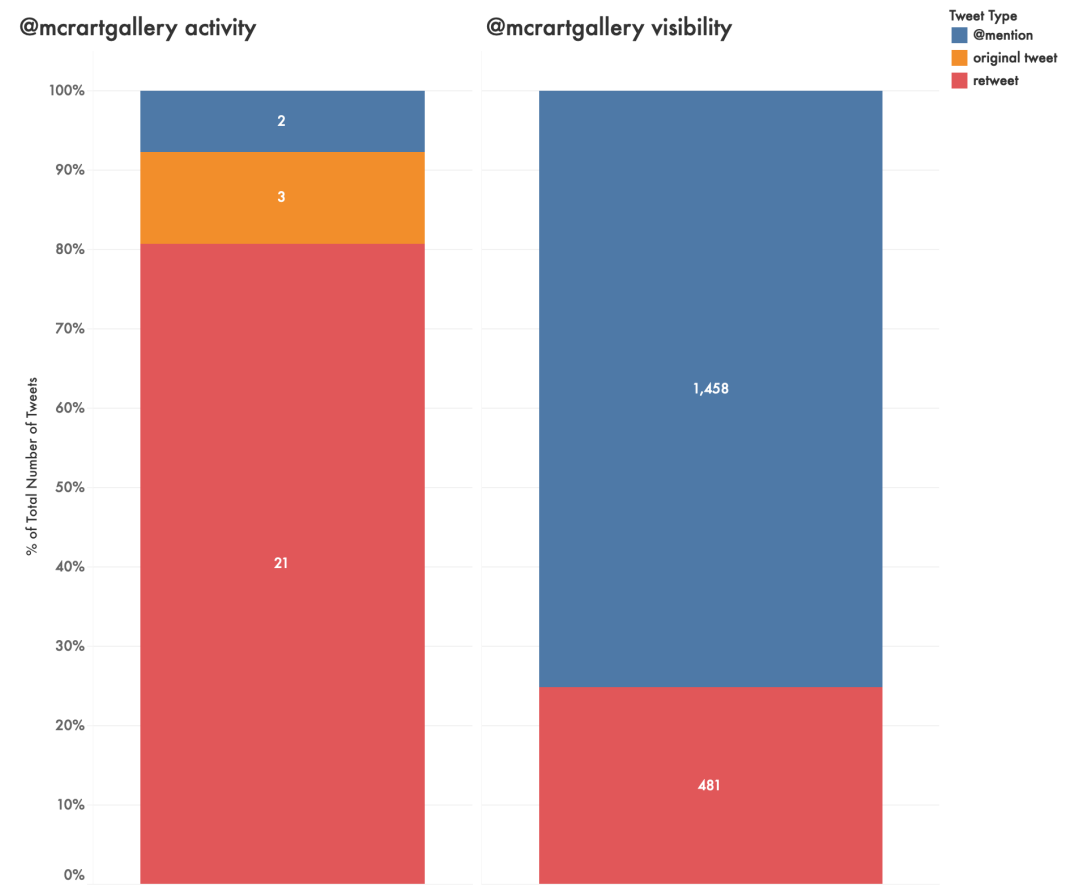

Figure 5. @mcrartgallery Activity and Visibility 


\subsection{Hashtags}

One way to influence Twitter conversation, and to increase the potential audience for certain content, is to use hashtags. The aim of the takeover event was to 'prompt conversation' - partly by encouraging visitors and audiences to share their thoughts online through the hashtag \#MAGSoniaBoyce. This way the conversation about the removal of Hylas and the Nymphs would reference the (then) upcoming Sonia Boyce exhibition. Only a quarter of tweets (26 per cent) included the \#MAGSoniaBoyce hashtag, which - despite being the most popular hashtag in the dataset - highlights a methodological issue of using social media data in research, as well as a practical issue for the Gallery.

The \#MAGSoniaBoyce hashtag is an institutional tag created by the Gallery for its users (including visitors, audiences, and staff) to share content in a specific and seemingly 'contained' space. In doing so, these users would be co-creating an institutional narrative in relation to the takeover event as well as any other activity related to the Sonia Boyce exhibition. From a methodological standpoint, using data collected only through this hashtag would provide a partial understanding of the Nymphgate community. Similarly, from a practical perspective, following or engaging only with the dialogue shared through this hashtag would give the Gallery a limited outlook on the effect of the takeover to online audiences. For these reasons I advocate for a broader collection of data, using various terms and phrases, to gain a more thorough understanding of an online conversation - from a research and from a practical perspective.

The second and third most popular hashtags are \#metoo and \#timesup, which indicate the presence of different, distinct communities whose interests and values intersect or overlap with the Nymphgate community. These shared communities create overlapping groups within the Nymphgate network that represent different perspectives on the main topic. In this case, however, these overlapping groups are formed as the central topic is affected by related events - such as media articles. The graph below (Figure 6.) shows the prominence of the top 20 hashtags in the dataset distributed on a timeline. Here we can see how the \#metoo and \#timesup tags are used as part of the Nymphgate dialogue only after the Brown and Jones articles are published.

Top 20 Hashtags Timeline

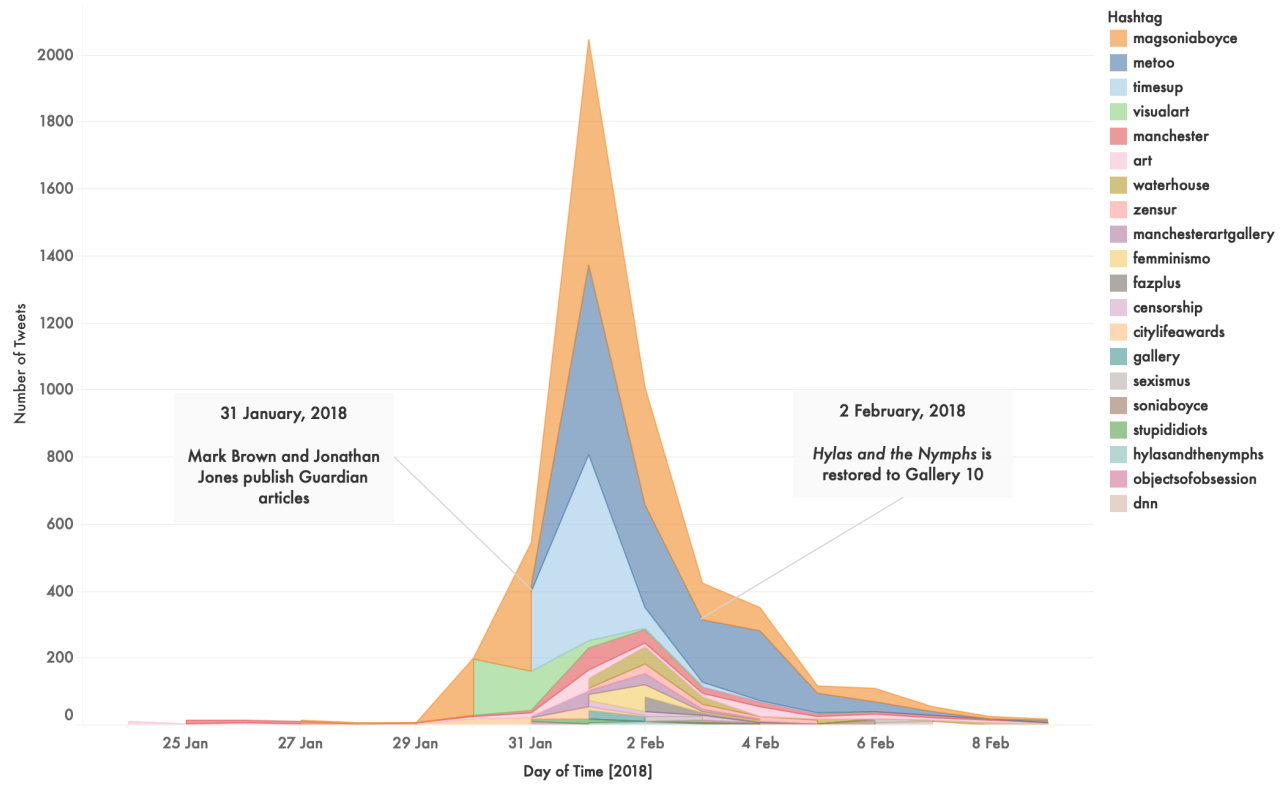

Figure 6. Top 20 Hashtags Timeline 
Hashtags and user trends are useful ways of studying the development of the Nymphgate network, especially as a way to start understanding the thematic trends in the conversation. To continue exploring the dialogue that followed the Gallery's takeover, I will focus now on the content of users' posts and the language of the responses as they shifted between outrage, accusations, and confusion.

\section{Conversation Themes}

To gain an understanding of the conversation beyond using Twitter metrics, I employed a coding software (NVivo) to study the content of each tweet collected as part of the Nymphgate network. The resulting codebook is divided into two main categories: themes and cases. These categories were further divided into their own sub categorical structures, which often overlapped with one another. Overall, the Nymphgate conversation is distributed between three main themes (Figure 7. below) that represent the most common accusations users made against the Gallery's removal of Hylas and the Nymphs. That is: of being an act based on feminist or antiquated moral ideologies (Feminism and Puritanism), of being an act of willful ignorance (Role Questions), and of being an act of censorship (Censorship). A smaller theme represents less poignant accusations and a minority of supportive responses (Other); and finally, a small percentage represents tweets that were captured with TAGS but are in no way related to the Gallery (Bycatch).

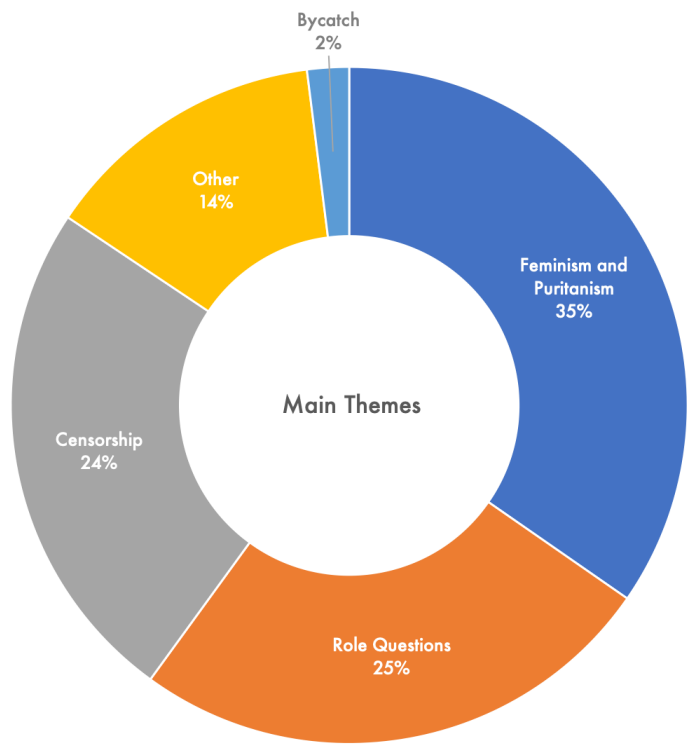

Figure 7. Main Themes

Cases are actors that are referenced in tweets. Cases were grouped according to their given human or nonhuman attributes (such as individual's roles or types of media), which led to eight main categories. Overall, users linked their comments and interactions to news and magazine articles (Article), some wrote their own blogs posts or linked back to the Gallery's blog (Website or Blog), whilst others extended comparisons to popularartworks (Artwork), and drew parallels between historical figures and Gallery staff members (Person) (Figure 8). A minority of users linked their comments to videos, institutions, and books; whilst others made connections to other (then) concurrent or upcoming exhibitions at the Gallery.

Although these categories and groupings may seem neatly structured, the reality of the conversation was quite complex. Users often made comments that bridged themes and cases together, whilst others made no comments at all (for example by using the "tweet button" on particular webpages ${ }^{17}$ ) - making the analysis of sentiment nearly impossible. In this section I aim to trace the development of the Nymphgate conversation through themes; whereas the following section will focus on the cases and their influence in the conversation. 
Article

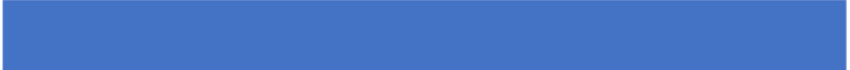

Web or Blog

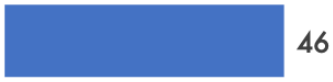

Artwork

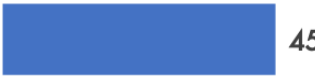

Person

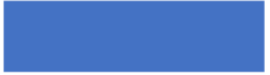

43

Video

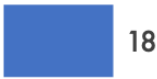

Event or Exhibition

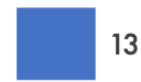

Institution

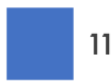

Book

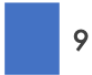

Figure 8. Case Categories

\subsection{Feminism and Puritanism}

'Feminism' is the most common theme found throughout the Nymphgate conversation - for the most part, users accused the Gallery and its staff of pushing a contemporary 'feminist-liberal agenda' to re-interpret and remove a historical work of art. From this perspective, the Gallery was brought into a debate where 'feminism' is a trope for 'the destruction of beauty' - both in art and in society. In the examples below, we see how 'feminism' transects other aspects in the Nymphgate conversation, bringing together cases (such as a digital representation of the removed painting in the link) and themes (such as questioning the authority of the curators). In such accusations there is a trend where the Gallery is brought into a debate indirectly (as seen in Tweet 647 below by the users' lack of tags), ${ }^{18}$ and directly (as seen in Tweet 165 below where the user tags two Gallery accounts) - adding further contention to the seemingly diametric question of activity versus inactivity in a Twitter debate.

'Feminism' polarized users in relation to the Me Too movement and (then) current events, such as the ban on darts walk-on girls and Formula One grid girls. On one hand some users blamed 'feminists' for pressuring organizations to change the way they work and who works for them; and on the other hand, users who identified themselves as feminists disapproved of the removal as a way to discuss the issues raised by Me Too and Time's Up. The common thread between these instances was a criticism over the decision to remove the painting based on its subject matter - in that it depicted semi-nude women - giving way to accusations of Puritanism and censorship.

In the most extreme cases where feminism was linked to censorship, users adopted a derogatory term to describe those involved: feminazi. In the Nymphgate community, this 
term was most often used by users in Spain and Chile, showing the geographical spread of this network. In less extreme cases, the accusations of feminism, Puritanism and censorship were conflated into a resentment of 'political correctness'. In this case, Nymphgate users bemoaned the removal of the painting as a feminist, puritan act of 'censorship' - that is, an example of 'PC culture' that 'has gone too far'. In these accusations we see again parallels to current events (grid girls and Me Too), criticism over curatorial and managerial decisions, as well as calls to action to fellow users - in the form of petitions and boycotts.

Feminists attack feminine Beauty. This

Waterhouse masterpiece of 'Hylas and the Nymphs' was removed from Manchester Art Gallery due to feminist pressure. Beauty is vanishing from our world because we live as though it did not matter. Beauty will always matter. https://t.co/yQjmIALjVv

Tweet 647
@MAGcurators @mcrartgallery Let's take back our culture from the grip of the Left. Who put them into power anyway? We are in a culture war with curators who seem to hate beauty. \#ManchesterArtGallery

\section{Figure 9. 'Feminism' Sample Tweets}

\subsection{Role Questions}

The second most popular theme is based around criticism of staff members and their roles in relation to the takeover and the collection, as well as of the Gallery and its role in society. Whilst some commented on the passive role of artworks (i.e. as objects meant to be looked upon only), others commented on their own capacities to make decisions (such as to be or not be offended by an artwork). As with the previous theme, 'Role Questions' intersects with other themes and cases throughout the conversation - weaving the Nymphgate narrative with contemporary as well as historical political and social contexts.

One of the effects of the takeover is that users could not reconcile the removal of Hylas and the Nymphs with their understandings of what an art gallery does. Many users considered the Gallery as a space for the display and custody of artworks, so removing the painting seemed like an affront to cultural heritage. Others were disappointed by the Gallery's 'lack of responsibility' as a publicly funded organization tasked with a publicly owned collection pointing to a mis-management of the institution and of cultural assets. In some instances users commented on the Gallery's hiring policies as a way to try to understand why the decision to remove the painting was taken, resulting in similar debates as in the previous theme around 'PC culture' and a 'pushy liberal agenda'.

@mcrartgallery You've made a terrible misstep with this. You've broken trust with the public over curating these pictures and drawn into serious question your fitness to continue to hold them @ClareGannaway \#MAGSoniaBoyce

Tweet 1692 @mcrartgallery would like to announce the temporary removal of @ClareGannaway's salary as a means of stimulating discussion about the publicity-hungry curators in publicly-funded jobs https://t. co/8PHicaN4AD 
Gannaway's role was questioned more than any other Gallery staff member, which stands to reason as she became the spokesperson for the takeover and as the voice of the Gallery in the media. Users were critical of her proficiency as a curator and accused her of not respecting or understanding art history, of utilizing the Me Too movement for her personal gain, and for meddling with artworks outside of her range of expertise. Mostly, users demanded the Gallery and Manchester City Council ${ }^{19}$ to review her position or to terminate it altogether.

One of the most troubling aspects of this conversation is the lengths to which some users went to defend their positions in discrediting or mocking Gannaway. For example, one particular user took Gannaway's likeness and created their own version of Hylas and the Nymphs where, instead of nymphs, several versions of the curator were seducing and abducting Hylas into the water. Despite the lengths and 'creative' responses that users had towards Gannaway, it is clear that members of this community showed contempt and mistrust towards her and the Gallery. Moreover, such criticism highlights the self-awareness of the Nymphgate community in their potential roles and agency in relation to the takeover. For example, some users were not only concerned with misguided decision-making, but they were also concerned that the Gallery took away their own ability to make decisions about the painting (literally and figuratively).

\subsection{Censorship}

One of the common threads in the accusations of 'feminism gone mad' and of the suitability of the Gallery's curators to manage public property, is that users viewed the physical removal of the painting as an act of censorship. In this theme users considered the removal as a political act similar to ones perpetrated by authoritarian regimes, often referring to the painting as 'degenerate art' or as a step towards 'burning books'. Mostly, comments of censorship seem to be an expression of fear and confusion - fear that 'Western' and 'traditional' principles are losing value, and confusion over whose extreme political beliefs are to blame. As a researcher, this theme was one of the most difficult to manage as users made racist and homophobic remarks to denigrate the takeover and those involved.

On the less radical end of the 'Censorship' comments spectrum, users turned to more mainstream (even fictional) examples to accuse the Gallery of sympathizing with movements and historical figures who specifically targeted artworks as a form of censorship. Users' examples varied from comparing the Gallery with the 'Big Brother' and the 'Ministry of Truth' (references to George Orwell's novel 1984), to comparing the removal as a modern version of the Catholic Church's 'Fig Leaf Campaign', to drawing parallels to the Nazi regime and their book burning campaigns. On the other end of the 'Censorship' spectrum were users who used racist remarks and verbally abusive language towards the Gallery and those involved in the removal. Most of these radical comments ranged between comparing the Gallery with the Taliban and ISIS, to suggesting that the removal was an act of 'bowing to pressure' from the Gallery's Muslim audiences, to verbal abuse aimed directly at the Gallery and staff members (including tagged posts).

In the Nymphgate community, users who adopted abusive and racist language, or that referenced media outlets such as Breitbart or InfoWars, are in the minority ( $<1$ per cent). These users, however, represent a sub-section of existing online communities that the Gallery managed to reach with their takeover event. Although the Gallery did not intend to reach such groups or even consider them as target audiences, it is necessary to acknowledge that they are potential audiences - both online and offline. The presence of this radical community within the Nymphgate network points to the 'knock-off' effect that social media can have with the right trigger words and a broadcasting algorithm. In this sense, it is necessary that the Gallery both reconcile with the technological affordances of these tools and with their political stance towards such potential audiences.

\subsection{Other}

The last overall category 'Other' in the thematic analysis of the Nymphgate conversation is composed of tweets that are not overwhelmingly accusatory of censorship, or competence, or of 'mad feminism' but were instead ambivalent, positive, or that were collected during the 
research period but are not related to the Gallery. Posts include comments about the subject and style of the removed artwork, images of the Gallery space, and visually creative responses to the takeover. Moreover, we see the influence of other media articles to the conversation after the painting was reinstated, whose authors were in favour of the takeover event.

\begin{abstract}
It's not amazingly well reported, though: it's only down temporarily and the (BAME) artist who selected it for removal isn't being discussed at all (on Twitter \& the guardian anyway) - which kind of highlights the point about what voices/perspectives we promote. \#MAGSoniaBoyce
\end{abstract}

Tweet 2320

\begin{abstract}
Wasn't quite sure what to think of the \#MAGSoniaBoyce fiasco until visiting the gallery yesterday; I don't think I've ever seen it so busy - nice to see the wider public contemplating and debating art. https://t.co/ AXSnuBy0k 1
\end{abstract}

Tweet 8431

\section{Figure 11. 'Other' Sample Tweets}

Despite the overwhelmingly negative responses in the Nymphgate conversation, a fraction of the comments were discernibly positive (1 per cent) and yet, these supporters used almost the same reasons as those who opposed it. Some were happy that the painting was removed as a way to re-contextualize the female form, others applauded the Gallery's move as a bold way to 'start a conversation', and others questioned their own fascination with Hylas and the Nymphs. Interestingly, the majority of positive comments were posted after a series of articles were published in favour of the takeover - namely two opinion pieces published in The Guardian, one by Gilane Tawadros ${ }^{20}$ and another by Sonia Boyce. ${ }^{21}$ Both articles had a mixed reception by the Nymphgate community, yet more users showed their support for the Gallery and for Gannaway after their publication. Up until this point, Boyce had been all but invisible in the Nymphgate conversation, even though she was integral to the event - a fact that did not go unnoticed in the conversation. Moreover, users posted positive tweets after visiting the Gallery and seeing visitors interact and respond to the removal through post-its and in person with each other.

\section{Conversation Cases}

Users' often referenced human and non-human 'cases' in their comments these range from articles and blog posts, artworks and exhibitions, to persons and institutions. In most instances users based their comments on articles by providing a link to them; in other cases, users compared the event to historical episodes and those involved in it to contemporary and historical individuals. Unsurprisingly, the top most referenced cases are those that have featured prominently in the conversation themes: Brown's article, Clare Gannaway, the Me Too movement, J. W. Waterhouse, and Hylas and the Nymphs. These are followed by other referenced articles, the Gallery's blog post where they published their public statements about the event, and one painting unrelated to the takeover (Whispering Eve, see Figure 12). These cases' popularity mirror not only the themes in the conversation, but also the most popular tweets as discussed earlier.

This list, however, leads to question which actors are silent in the online conversation and why. Similarly, it raises questions about the potential influence of the Nymphgate network to the Gallery's offline spaces. Although these latter queries are out of scope for this article, I explore here which actors are silent online and how this perception can erroneously be mistaken as a lack of influence. In this sense, I argue that the most influential actors in the Nymphgate conversation are those who are not necessarily active online but were instrumental to the event - namely, individuals such as Sonia Boyce, Family Gorgeous, the Gallery's Web and Social Media Manager, any other staff member who participated during the event; as well as the Manchester City Council. 


\section{Top 20 Cases}

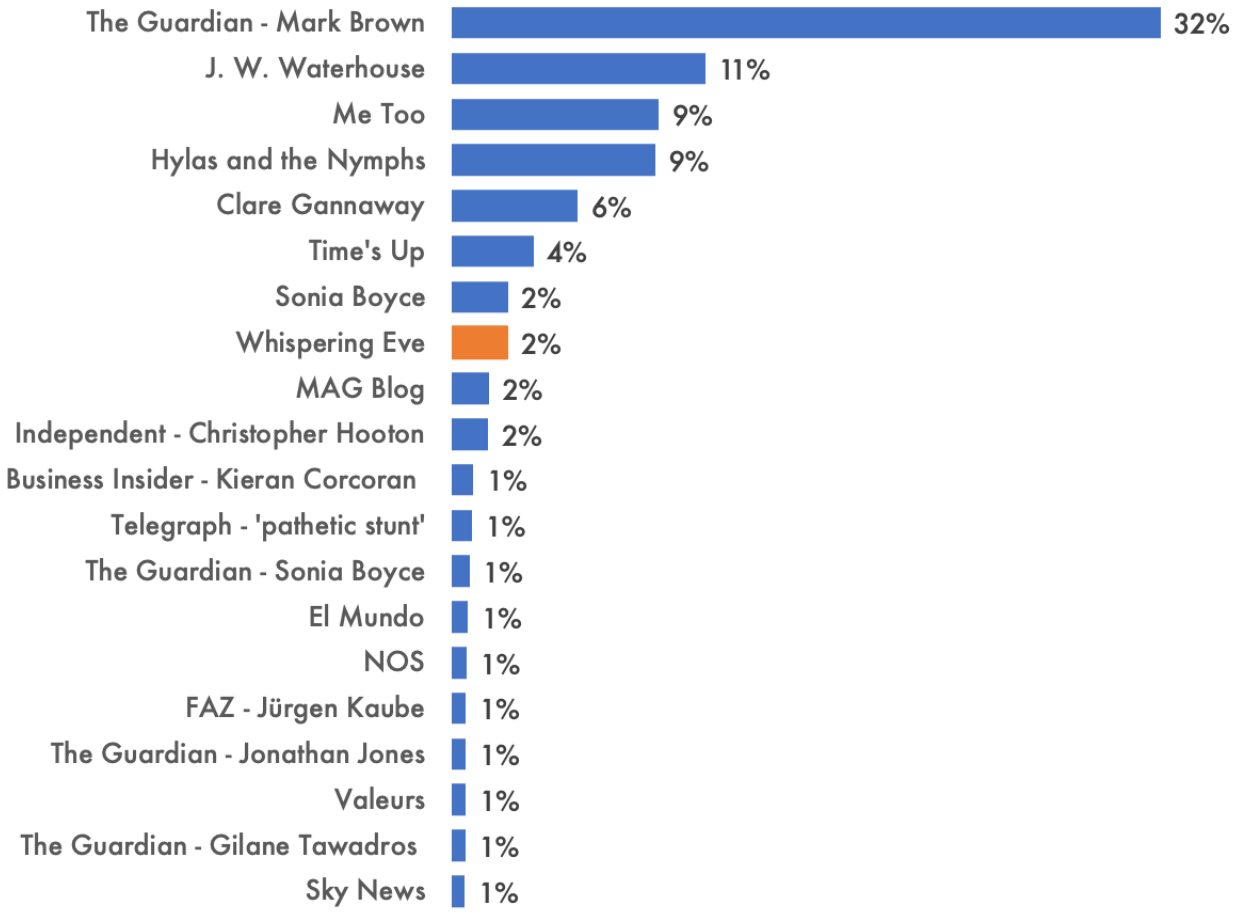

Figure 12. Top 20 Cases

\section{1. 'Silent' Influencers}

One actor that is 'silent' from this online space and narrative is the Manchester City Council (MCC), the local government entity that 'sets the budget for the Art Galleries and is involved in major decisions about the city's galleries'. ${ }^{22}$ It can be assumed, then, that MCC is a very influential actor in their relationship to the Gallery and one that plays an operational role in the Gallery's brand network. MCC, however, is not active in the Nymphgate conversation and so their inactivity may be construed as absence. Alternatively, MCC appears in users' demands to dismiss Gannaway and the Gallery's leadership, as well as to reconsider their allotment of public funds. More importantly, MCC is brought into the conversation in a BBC report stating that they 'announced that the painting would return to the wall', ${ }^{23}$ leading users to believe that the Gallery was mandated to reinstate the painting (Figure 13).

Gannaway became the spokesperson for the event and for the Gallery (at this time) for better and for worse. She was invited to participate in other interviews and to further explain the motivations for the removal. Yet again her comments on further outlets, such as her interview with BBC Radio $4,{ }^{24}$ were used to kindle and shape the conversation online drawing more criticism and abuse towards her and the Gallery. Critics (and the minority of supporters) who were keen on ensuring that the Gallery and Gannaway saw their comments, opted for @mention tweets tagging the Gallery's institutional accounts (@mcrartgallery, @ magcurators, and@MAGGallery cafe) and Gannaway's account (@ClareGannaway).Despite Gannaway's visibility, and offline activity, her online presence overshadowed any other staff member who may have been involved in the takeover event. Although the Gallery hinted at the group decision-making process that led up to the removal in a tweet (Figure 14), it is difficult to understand how the actions of particular actors offline influenced how the Nymphgate network and narrative took shape by studying social media data alone. 
And it's back. Most interestingly, reading between the lines, it seems that Manchester City Council, as owners of the gallery, have overruled@mcrartgallery management. Well done everyone. This time, we won, cultural elitism lost. https://t.co/vXcAvqowco

Tweet 13226
Someofthecriticism the Gallery received was in part for their lack of activity online and in part for their 'selective' activity. Users accused them of only retweeting and liking a handful of posts that had comments that supported the event, furthering users' concernsofcensorship. The Gallery's Web and Social Media Manager admitted being overwhelmed by the online responses they were receiving (through Twitter, on the blog, and other social media platforms), which led to a conscious decision to stop responding to comments (Arias and Grimes 2018). This decision to step back from the online conversation the Gallery actively sought to have as part of the takeover, was as influential as Gannaway's comments in the media. The few tweets that the Gallery did post, however, provide small evidence of the other performative acts that took place that evening, as well as its performers and the participating crowd. One tweet in particular shows a video of the painting being wheeled away surrounded by Boyce and her recording team; this video is the only portrayal of Boyce in action during the event in the dataset. It is indicative of her artistic practice (that is 'all about bringing people together in different situations to see what happens' ${ }^{\prime 25}$ ) and her perceived absence in the online conversation.

Hylas and the

MCR Art Gallery
Replying to
Your point is valid. However, it's the people's
gallery. This action and discourse is not the
work of iconoclastic staff, it's the result of
many people coming together to prompt
conversation about how we display and
interpret artworks in Manchester's public
collection.
9:56 Am - 28 Jan 2018

Figure 14. Tweet by @mcrartgallery
Nymphs was removed for seven days and during this time the Nymphgate community flooded their conversation with digital versions of the painting. So, although it was absent in its physical environment, this artwork was still able to influence the conversation through the actions of those who tweeted its image. This was not the case, however, for Sonia Boyce or for the drag collective, Family Gorgeous, who joined her for the takeover. These artists were integral for the event and yet, they

were all but absent in the online conversation - save for a tweet from the Gallery's main account, another from one of the performers, and two homophobic articles. I argue that as the Nymphgate conversation took shape, and the Gallery became overwhelmed with the Twitter responses, the takeover event and its aims were overshadowed by the removal of the painting - to the point that the removal itself became the event online. 


\section{Discussion and Conclusion}

The takeover at the Manchester Art Gallery was supposed to be a business-as-usual event, but then the proverbial you-know-what hit the fan giving way for an online community to take shape with a narrative that effectively left the Gallery out of the picture. In this article, I have explored how the Nymphgate community and conversation were influenced by a series of human and non-human actors, as well as by the technological affordances of the platform. I have illustrated how, although the Nymphgate network was instigated by the Gallery, the narrative created by the community was shaped in the continuous performances of other actors. In other words, although the Gallery set out to organize a community around their takeover and to create a discourse stemming from this event, they effectively 'deleted' (or 'silenced') themselves from the conversation.

The information created and shared in the Nymphgate network, then, is the result of the asymmetric relationships between a handful of influential actors (in their perceived activity/ inactivity) and the behaviours afforded by the Twitter platform. Brown's article is one of the most influential actors within the network - it mediatized the takeover whilst (arguably) providing the first kernels of criticism. The article brought together context around the Gallery's decisionmaking processes, including staff details and contemporary socio-cultural environments, in relation to the takeover. The article is only influential, however, due to repeat sharing (either through retweets or in original posts) and a technology that favours and promotes a continuous ability to spread valuable content. This way, Brown's article was influential and valuable in the Nymphgate community as long as users continued to share it - thereby giving shape to this network in size, themes, and cases.

Another influential actor in the Nymphgate conversation is the Manchester Art Gallery (@mcrartgallery). Similar to Brown's article, the Gallery's influence rested on other users' actions, such as making the Gallery visible through tagging and retweeting. Despite organizing an event to prompt a 'conversation' with audiences, the Gallery effectively silenced themselves from the community that was moulded by and in this conversation. If the Gallery had continued to participate (even after a hiatus), then 'in principle' as Law proposed (Law 1999: 4), the Nymphgate narrative could have read much differently and the Gallery's legitimacy would not have been questioned. Speaking in these terms, however, points to a limitation of this case study. By looking only at social media data, I am not able to discern why the Gallery decided to stop participating in the online conversation, nor what was the intended role of social media for the takeover.

The Gallery created an environment where they asked their audiences to reconsider the existing interpretative framework and to create together a narrative that reflected contemporary social and political contexts. In doing so, they entered a transactional relationship that shifted the existing relationships between several actors within the confines of the event. However, in the ensuing conversation the Gallery was absent and so the resulting negative and accusatory narrative stemmed mainly from its audience's continuous performances. What is unclear at this stage is how the takeover was framed from an organizational perspective - that is, the decisions that led up to the event, the intended roles of those involved in it (including social media), and the intent for the resulting narrative. In this sense, it is unclear how the Gallery valued their collaboration with audiences and how re-negotiating their relationships would translate outside the limits of the event.

The Nymphgate conversation could be used as a learning point not only by the Gallery but by other institutions that seek to use social media to mediate relationships with audiences and visitors. These technologies may lead to reframing the 'power relationships' (Meecham 2013) between actors who help shape cultural institutions - be they audiences, policymakers, collections, or staff members. Despite the 'democratisation' potential of social media, however, the extent of their influence lie with a handful of actors and their continuous performances. This conditional influence is particularly relevant in collaborative activities, where their success depends on the continuous performance by the organizer and its ongoing relations with its participants. Whilst the Gallery created an opportunity to shift the relationships between their contemporary visitors and historical collection through a conversation, they did not maintain the expectations they set by being silent online. 
Framing the Nymphgate conversation from an organizational perspective requires a further investigation of the Gallery's broader network, particularly on the overall role of social media within the institution. In other words, although this study explored the resulting narrative from the Gallery's takeover, it does not address the context that led up to it nor any potential impact it may have on the Gallery's organizational strategy. To address this limitation, my next study will incorporate interviews with Gallery staff members to gain their perspectives on the takeover and how it relates to the institution outside its limited scope. With further study, I hope to understand how the Nymphgate conversation is valued over time and whether this network has an impact on the Gallery's existing relationships with social media and the actors associated with it.

Received: 30 September, 2019 Finally acceped 3 February, 2020

\section{Notes}

${ }^{1}$ Henceforward, the Manchester Art Gallery may also be referred to as the Gallery.

${ }^{2}$ Manchester Art Gallery, 'Presenting the female body: Challenging a Victorian fantasy. Manchester Art Gallery', Manchester Art Gallery Blog, 27 January 2018. http:// manchesterartgallery.org/blog/presenting-the-female-body-challenging-a-victorianfantasyl, accessed 2 February 2018.

${ }^{3}$ Martin Hawksey, 'Twitter Archive Google Sheets (TAGS)', TAGS website, no date. https:// tags.hawksey.info/get-tags/, accessed 31 August 2018.

${ }^{4}$ Twitter Inc, 'The Twitter Rules', Twitter Help Website, no date. https://help.twitter.com/en/ rules-and-policies/twitter-rules, accessed 18 June 2018.

${ }^{5}$ Jean Burgess, Axel Bruns, Tim Highfield, 'Social Media Analytics: Using Data to Understand Public Conversations', FutureLearn, 2018. https://www.futurelearn.com/courses/socialmedia-analytics, accessed 13 June 2018.

${ }^{6}$ Leanne Townsend and Claire Wallace, 'Social Media Research: A Guide to Ethics', The University of Aberdeen, 2016. https://www.gla.ac.uk/media/media_487729 en.pdf, accessed 12 April 2018.

7 Twitter Inc, 'Twitter Rules'.

8 Twitter Inc, 'Twitter Terms of Service', 2018. https://twitter.com/content/twitter-com/legal/ en/tos.html accessed 18 June 2018.

${ }^{9}$ Mark Brown, 'Gallery removes naked nymphs painting to "prompt conversation"', The Guardian, 31 January 2018. http://www.theguardian.com/artanddesign/2018/jan/31/manchester-artgallery-removes-waterhouse-naked-nymphs-painting-prompt-conversation accessed 3 February 2018.

${ }^{10}$ Gallery 10 has since been renamed as: 'Whose Power on Display?'

${ }^{11}$ Emine Saner, 'Grid girls': F1 follows darts by calling time on women in hotpants', The Guardian, 2 February 2018. https://www.theguardian.com/world/2018/feb/02/grid-girlsf1-follows-darts-by-calling-time-on-women-in-hotpants, accessed 5 December 2018.

${ }^{12}$ Brown, 'Gallery removes naked nymphs painting to "prompt conversation"'.

${ }^{13}$ Brown, 'Gallery removes naked nymphs painting to "prompt conversation"'.

${ }^{14}$ Rebekah Carter, 'Exploring the Top 10 Twitter Metrics You Should Be Tracking Today', Sprout Social, 30 March 2018. https://sproutsocial.com/insights/twitter-metrics/, accessed 11 December 2018. 
${ }^{15}$ Clay Shirky, 'Shirky: Power Laws, Weblogs, and Inequality', Clay Shirky's Writings About the Internet Economics \& Culture, Media \& Community, 8 February 2003. http://www. shirky.com/writings/powerlaw weblog.html, accessed 12 December 2018.

${ }^{16}$ Manchester Art Gallery, 'Presenting the female body'.

${ }^{17}$ The 'Tweet Button' is a tool that Twitter offers for website developers and users. In many cases, the Tweet Button provides a text parameter that autopopulates a tweet with particular text, such as the title of the webpage. For example, the Tweet Button included in the webpage that hosts Mark Brown's article, prompts an auto-populated tweet with the text 'Gallery removes naked nymphs painting to "prompt conversation"' and a link to the article. Twitter Inc, 'Tweet Button', 2019. https://developer.twitter.com/en/docs/twitterfor-websites/tweet-button/overview.html, accessed 15 January 2019.

${ }^{18}$ Tagging here implies that a user @mentions another user. The @mention then becomes a tag.

${ }^{19}$ The Manchester Art Gallery is a branch of the Manchester City Council.

${ }^{20}$ Gilane Tawadros, 'Removing nymphs from a gallery is provocative - but does not merit contempt', The Guardian, 2 February 2018. http://www.theguardian.com/ commentisfree/2018/feb/02/nymphs-manchester-art-gallery-perspective-censorship, accessed 3 February 2018.

${ }^{21}$ Sonia Boyce, 'Our removal of Waterhouse's naked nymphs painting was art in action', The Guardian, 6 February 2018. https://www.theguardian.com/commentisfree/2018/feb/06/

\section{References}

Arias, M. P. and Grimes, M. (2018) ‘\#Nymphgate: Dealing with Negative Media Attention’, Museums Association 2018 Conference, Belfast.

Callon, M. (1986) 'Some Elements of a Sociology of Translation: Domestication of the Scallops and the Fishermen of St Brieuc Bay', in John Law (ed) Power, Action and Belief: A New Sociology of Knowledge?, Sociological Review Monograph 32, 196 233, London: Routledge \& Kegan Paul.

(1999) 'Actor Network Theory - The Market Test', The Sociological Review, 47 (S1) 181-95.

Carr, C. T. and Hayes, R. A. (2015) 'Social Media: Defining, Developing, and Divining', Atlantic Journal of Communication, 23 (1) 46-65.

van Dijck, J. (2013) The Culture of Connectivity: A Critical History of Social Media, New York: Oxford University Press.

Drotner, K. and Schrøder, K. (2013) 'Introduction Museum Communication and Social Media The Connected Museum', in Kirsten Drotner and Kim Schrøder (eds) Museum Communication and Social Media: The Connected Museum, Routledge Research in Museum Studies, 1-14, New York: Routledge.

Kelly, L. (2013) 'The Connected Museum in the World of Social Media', in Kirsten Drotner and Kim Schrøder (eds) Museum Communication and Social Media: The Connected Museum, Routledge Research in Museum Studies, 54-71, New York: Routledge.

Kidd, J. (2011) 'Enacting engagement online: framing social media use for the museum', Information Technology \& People, 24 (1) 64-77 http://www.emeraldinsight.com. libproxy.ucl.ac.uk/doi/full/10.1108/09593841111109422. 
Kozinets, R. V. (2015) Netnography: Redefined, $2^{\text {nd }}$ edition, Los Angeles: SAGE.

Latour, B. (2005) Reassembling the Social: An Introduction to Actor-Network-Theory, Clarendon Lectures in Management Studies, Oxford; New York: Oxford University Press.

Law, J. (1994) Organizing Modernity, Oxford: Blackwell.

(1999) 'After ANT: Complexity, Naming and Topology', in John Law and John Hassard (eds) Actor Network Theory and After, Sociological Review Monographs, 1-14, Oxford: Blackwell.

Meecham, P. (2013) 'Social Work: Museums, Technology, and Material Culture', in Kirsten Drotner and Kim Schrøder (eds) Museum Communication and Social Media: The Connected Museum, 33-53, Routledge Research in Museum Studies, New York: Routledge.

Phillips, W. and Milner, R. M. (2017) Ambivalent Internet: Mischief, Oddity, and Antagonism Online, 1st Edition, Cambridge, UK; Malden, MA: Polity Press.

Poell, T. and Borra, E. (2012) 'Twitter, YouTube, and Flickr as Platforms of Alternative Journalism: The Social Media Account of the 2010 Toronto G20 Protests', Journalism, 13 (6) 695-713.

\section{Author}

Maria Paula Arias is currently a PhD Student at the University of Manchester. She is interested in the relationships between branding, social media, and organisational management in museums and galleries. Her current research is focused on the potential impacts of social media tools and audiences to museums' brands - her case study is the Manchester Art Gallery. Furthermore, she is an advocate for the ethical use of social media data in research and decision-making processes.

mariapaula.arias@postgrad.manchester.ac.uk

+44 (0) 7593310483

Twitter: @ariasmari 